\title{
Rat Malonyl-CoA Decarboxylase; Cloning, Expression in E. coli and its Biochemical Characterization
}

\author{
Gha Young Lee, Young Yil Bahk and Yu Sam Kim* \\ Department of Biochemistry, College of Science, Protein Network Research Center, Yonsei University, Seoul 120-749, Korea
}

Received 16 October 2001, Accepted 26 November 2001

\begin{abstract}
Malonyl-CoA decarboxylase (E.C.4.1.1.9) catalyzes the conversion of malonyl-CoA to acetyl-CoA. Although the metabolic role of this enzyme has not been fully defined, it has been reported that its deficiency is associated with mild mental retardation, seizures, hypotonia, cadiomyopathy, developmental delay, vomiting, hypoglycemia, metabolic acidosis, and malonic aciduria. Here, we isolated a cDNA clone for malonyl CoA decarboxylase from a rat brain cDNA library, expressed it in $E$. coli, and characterized its biochemical properties. The full-length cDNA contained a single open-reading frame that encoded 491 amino acid residues with a calculated molecular weight of 54, 762 Da. Its deduced amino acid sequence revealed a $65.6 \%$ identity to that from the goose uropigial gland. The sequence of the first 38 amino acids represents a putative mitochondrial targeting sequence, and the last 3 amino acid sequences (SKL) represent peroxisomal targeting ones. The expression of malonyl $\mathrm{CoA}$ decarboxylase was observed over a wide range of tissues as a single transcript of $2.0 \mathrm{~kb}$ in size. The recombinant protein that was expressed in $E$. coli was used to characterize the biochemical properties, which showed a typical Michaelis-Menten substrate saturation pattern. The $K_{m}$ and $V_{\max }$ were calculated to be $68 \mu \mathrm{M}$ and $42.6 \mu \mathrm{mol} / \mathrm{min} / \mathrm{mg}$, respectively.
\end{abstract}

Keywords: Malonyl-CoA decarboxylase, Cloning, Expression

\section{Introduction}

Malonyl-CoA decarboxylase activity (EC 4.1.1.9, MCD), which catalyzes the decarboxylation of malonyl CoA to acetyl CoA, has been observed in a variety of organisms from microbes to mammals (Kim and Kolattukudy, 1978a, b; An and Kim, 1998; Sacksteder et al., 1999). However, its physiological role is unclear. The enzyme from the goose

*To whom correspondence should be addressed.

Tel: 82-2-2123-3448; Fax: 82-2-392-3488

E-mail:yskim@yonsei.ac.kr uropygial gland and rat liver, especially in mitochondria and cytosol, has been extensively studied and characterized (Kim and Kolattukudy, 1978a, b). Recently, malonyl CoA has been in the spotlight as a regulator of the maintenance of mammalian cell function. Especially in the mitochondrial enzyme from geese, it has been proposed that this enzyme might act in removing intra-mitochondrial malonyl CoA, which is non-specifically generated by the action of propionyl CoA carboxylase (Kim and Kolattukudy, 1978b). If malonylCoA is accumulated once, then the key mitochondrial enzymes, such as methylmalonyl-CoA mutase (Babior, 1973) and pyruvate carboxylase (Scrutton and Utter, 1967), could be inhibited. In the case of the cytosolic form, the evidence showed that it participates in the synthesis of methyl branched-chain fatty acids. In the goose uropygial gland, because methylmalonyl CoA is the only chain that elongates the substrate for fatty acid synthesis, this enzyme activity brings about the production of multimethyl-branched fatty acids (Kim and Kolattukudy, 1978a). In addition, a pivotal role for malonyl-CoA decarboxylase in mammalian metabolism is suggested by the severe phenotypes of patients who lack this enzyme activity (Hann et al., 1986; Krawinkel et al., 1994; Ozand et al., 1994; Gregg et al., 1998). MalonylCoA decarboxylase deficiency, also known as malonic aciduria, is a genetic disorder that is characterized by developmental delay, cardiomyopathy, mental retardation, and in its more severe forms, neonatal death. These patients show several phenotypes that are similar to deficiencies in mitochondrial fatty acid oxidation, including diet-induced and infection-induced vomiting, seizures, hypoglycemia, and organic aciduria, as well as cardiomyopathy (Yano et al., 1997).

Recently, it was suggested that the regulation of the cellular malonyl CoA level is one of the important physiological and cellular events, especially liver energy metabolism. As MCD is involved in the regulation of the cellular malonyl CoA level, this enzyme may play an essential role in regulating energy utilization in response to various nutritional changes and/or pathological states. 
MCD activity was detected in the cell extract of bacteria, such as Pseudomonas fluorescens and Acinetobacter calcoaceticus, which are grown on the malonate as a sole carbon source (Byun and Kim, 1995). Recently we cloned and expressed the first bacterial MCD from Rhizobium trifolii (An et al., 1999). Thus, it would be worthwhile to have more information on MCD of higher organisms other than just bacterial sources. In this study, we describe the cloning of the full-length cDNA for a novel rat $\mathrm{MCD}$, its expression of the recombinant protein in E. coli, and its biochemical characterization of the recombinant protein.

\section{Materials and Methods}

Strains and library Rat cDNA library (Uni-ZAP ${ }^{\circledR}$ XR LibraryCustom and Premade Libraries) was purchased from Stratagene (La Jolla, CA). Escherichia coli XL-1 Blue MRF' (Stratagene) was used to screen the cDNA library of the rat brain as a host strain (Sambrook et al., 1989). The ExAssist helper phage with the SOLR $^{\mathrm{TM}}$ strain was used to allow efficient in vivo excision of the pBluescript phagemid from the Uni-ZAP XR vector.

Preparation of homologous probe In order to clone the malonyl-CoA decarboxylase (MCD) gene, a homologous primer was initially prepared by means of PCR using a EST sequence that was similar to the mRNA sequence of Malonyl-CoA decarboxylase. The two prepared primers were the sense primer (5'-CTGAGAAGCTGGCACAGGCA-3') and antisense primer (5'-AAGTTGGCCACTGGATTGAG-3'). A PCR product was prepared by using the following PCR procedure and primers. The reaction mixtures $(50 \mu \mathrm{l})$ for PCR contained $100 \mathrm{ng}$ of the rat brain cDNA library, $20 \mu \mathrm{M}$ of each primer, 2.5 unit Taq polymerase, 2 $\mathrm{mM}$ of each deoxynucleotide triphosphate, and $5 \mu \mathrm{l}$ of a 10X PCR reaction buffer $(\mathrm{BM})$. The reaction was run with the following program using Techne PROGENE: 1 cycle $/ 2 \mathrm{~min}$ at $95^{\circ} \mathrm{C}$ : 30 cycles $/ 20 \mathrm{~s}$ at $95^{\circ} \mathrm{C}, 30$ cycles $/ 40 \mathrm{~s}$ at $58^{\circ} \mathrm{C}, 30$ cycles $/ 60 \mathrm{~s}$ at $72^{\circ} \mathrm{C}: 1$ cycle $/ 7 \mathrm{~min} 72^{\circ} \mathrm{C}$. The $106 \mathrm{bp}$ PCR product was cloned in a pCR ${ }^{\mathrm{TM}}$ 2.1 vector according to the manufacturers protocol, and sequenced. The PCR product was radiolabeled with $\left[\alpha-{ }^{32} \mathrm{P}\right] \mathrm{dCTP}$ using the Prime-a Labeling system (Promega) and used for screening the cDNA library.

Screening with isotope labeled probe The host cell was infected with $4-5 \times 10^{4}$ pfu of phage and plated onto a LB plate. After incubation at $37^{\circ} \mathrm{C}$ overnight, the plaques were transferred onto a transfer membrane. DNA was cross-linked to the membrane by a UV cross-linker. The membrane was hybridized $(6 \times \mathrm{SSC}, 0.1 \%$ SDS, and $5 \times$ Denhardt's solution) with the $\left[{ }^{32} \mathrm{P}\right]$-labeled probe at $65^{\circ} \mathrm{C}$ overnight. The membrane was washed, exposed to film, and developed. The positive $\lambda$ plaques were isolated. This phage was combined with the ExAssist helper phage $\left(>1 \times 10^{6} \mathrm{pfu} / \mu \mathrm{l}\right)$ and $E$. coli XL1-blue MRF'. After incubation of the mixture at $37^{\circ} \mathrm{C}$, the phage supernatant was added to SOLR cells, then the mixture was plated onto a LB-ampicillin agar plate. After incubation at $37^{\circ} \mathrm{C}$ overnight, a single colony was picked-up, transferred to a LB broth that contained ampicillin, and incubated at $37^{\circ} \mathrm{C}$ overnight. From the culture broth, DNA was prepared using the alkaline lysis method. DNA was treated with several restriction enzymes, like EcoRI, XhoI, and separated by electrophoresis on a $1 \%$ agarose gel.

Sequencing of cloned genes The plasmid DNA was isolated and purified using a Qiaprep Spin Miniprep Kit from Qiagen (Valencia, USA). PCR was performed with purified DNA as a template, M13 reverse and M13 forward (-20) primers, and Dye Terminator Cycle Sequencing Ready mixture (Perkin Elmer) according to the manufacturer's instructions. The PCR product was sequenced using a ABI PRISM 377 automatic sequencer.

Northern blot analysis and semi-quantitative RT-PCR Northern blot analysis was performed using standard protocols and rat multitissue Northern blots from CLONTECH (Palo Alto, USA). The rat MTN blot (CLONTECH) was hybridized with previously prepared $106 \mathrm{bp}$ probes at $65^{\circ} \mathrm{C}$ overnight in a hybridization solution $(6 \times \mathrm{SSC}, 0.1 \% \mathrm{SDS}$, and $5 \times$ Denhardt's solution). On the following day, the membrane was washed twice with $2 \times \mathrm{SSC}$, $0.05 \% \mathrm{SDS}$ at room temperature, then twice at $65^{\circ} \mathrm{C}$ with $0.1 \times$ SSC, $0.1 \%$ SDS. Each washing step took $20 \mathrm{~min}$. Autoradiography was performed for $24 \mathrm{~h}$ at $70^{\circ} \mathrm{C}$. Semi-quantitative RT-PCR was performed using total RNA from the various rat tissues. The firststrand cDNA was synthesized using the M-MLV RT (GibcoBRL) from $1 \mu \mathrm{g}$ of total RNA, and amplified using the primers that spanned the regions between nucleotides 525 and 795 of the rat MCD cDNA sequence. Primers 5'-GCTGCCTTCTCTTGTGACA AA-3' and 5'-CACGCCACAGCTTTCCAGA-3', which amplify $531 \mathrm{bp}$ of the rat GAPDH mRNA, were included in an individual RT-PCR reaction as an internal standard. The RT-PCR products were separated by agarose gel.

Expression of malonyl-CoA decarboxylase gene in E.coli The vector pGEX-4T (Pharmacia, Buckinghamshire, UK) was digested with BamHI and EcoRI. The $M C D$ gene was prepared by PCR from cloned genes using $p f u$ polymerase (Stratagene) and two primers that contained $B a m \mathrm{HI}$ and $E c o R \mathrm{I}$ at each end respectively (5'-GATGGATCCATG CGAGGCTTGGGGCCAAG-3' and 5'-A GAATTCTAGAGTTTGCTGTTGCTCTG-3'). The amplification product was digested with $B a m \mathrm{HI}$ and $E c o$ RI. The insert and vector were ligated, and the recombinant plasmid was introduced into the E. coli BL21 competent cell. The expression and purification of the GST-fused enzyme was carried out according to the manufacturers instructions (Pharmacia, Buckinghamshire, UK). The cultured cells were induced by the addition of $1 \mathrm{mM}$ IPTG, and the cells were harvested and sonicated. Bacterial cell lysates were loaded on a Gluthathione Sepharose 4B RediPack. The fusion protein that was bound to the matrix was cleaved with thrombin for $18 \mathrm{~h}$ at $22^{\circ} \mathrm{C}$. The supernatants were assayed for enzyme activity.

Determination of malonyl-CoA decarboxylase activity MalonylCoA decarboxylase activity was assayed by measuring the rate of production of acetyl-CoA spectrophotometrically by coupling the decarboxylase with malate dehydrogenase and citrate synthase (Kolattukudy et al., 1981). The reaction mixture contained $40 \mathrm{mM}$ sodium phosphate ( $\mathrm{pH} 7.0), 0.2 \mathrm{mM}$ dithiothreitol, $4 \mathrm{mM}$ malate, $0.2 \mathrm{mM} \mathrm{NAD}^{+}, \quad 0.2 \mathrm{mM}$ malonyl-CoA, 20 unit malate dehydrogenase, 4 unit citrate synthase, and malonyl-CoA decarboxylase preparation in a total volume of $1.0 \mathrm{ml}$. The reaction 
TTG

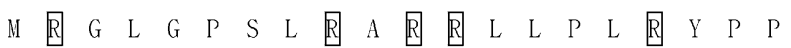

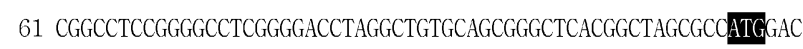
目 121 GAGCTGCTACGGGGAGCCGTGCCACCCACGCCGGCCTACGAGCTGCGCGAGAAGACGCCG $\begin{array}{llllllllllllllllllll}\text { E } & L & L & R & R & A & V & P & P & T & P & A & Y & E & L & R & E & K & T & P\end{array}$ 181 GCCCCGGCCGAGGGGCAGTGCGCGGACTTCGTGAGCTTTTACGGCGGCCTGGCCGAGGCG

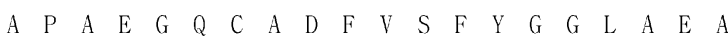
241 GCCCAGCGCGCCGAGCTGCTCGGCCGCCTGGCTCAGGGCTTCGGCGTGGATCACGGCCAG

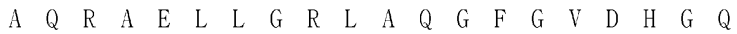
301 GTAGCGGAGCAGAGCGCCGGAGTGCTGCAGCTGCGCCAGCAGTCGCGCGAGGCGGCCGTG

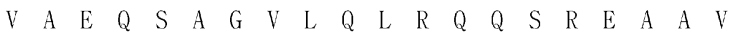
361 CTGCTGCAGGCAGAGGACCGGCTACGCTATGCCCTCGTGCCGCGATACCGTGGCCTCTTC

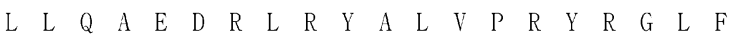
421 CACCACATCAGTAAGCTGGACGGCGGCGTGCGCTTCCTGGTACAGCTGCGGGCCGATCTG

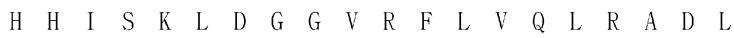

481 CTGGAGGCGCAGGCCCTCAAGCTGGTGGAAGGGCCGCACGTCCGGGAAATGAACGGAGTG

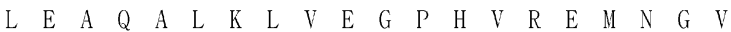
541 CTAAAAAGCATGCTGTCCGAGTGGTTCTCCTCTGGCTTCCTGAACCTGGAGCGGGTCACC

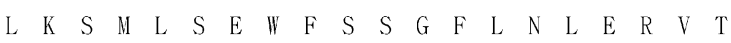
601 TGGCACTCGCCCTGTGAGGTGCTTCAGAAGATCAGCGATTGTGAGGCTGTGCAGCCTGTG $\begin{array}{llllllllllllllllllll}W & H & \mathrm{~S} & \mathrm{P} & \mathrm{C} & \mathrm{E} & \mathrm{V} & \mathrm{L} & \mathrm{Q} & \mathrm{K} & \mathrm{I} & \mathrm{S} & \mathrm{D} & \mathrm{C} & \mathrm{E} & \mathrm{A} & \mathrm{V} & \mathrm{Q} & \mathrm{P} & \mathrm{V}\end{array}$ 661 AAAAACTGGATGGACATGAAGCGGCGTGTGGGGCCATACCGGAGGTGTTACTTCTTCTCC

$\begin{array}{llllllllllllllllllll}K & N & \text { V } & M & \text { D } & \text { M } & K & R & R & V & G & P & Y & R & R & C & Y & F & F & S\end{array}$ 721 CACTGCTCCACCCCCGGGGACCCCCTGGTTGTTCTGCATGTGGCTCTGACCGGTGACATT $\begin{array}{llllllllllllllllllll}H & C & S & T & P & G & D & P & L & V & V & L & H & V & A & L & T & G & D & I\end{array}$ 781 TCCAACAACATCCAGAGCATTGTGAAAGAGTGCCCTCCGTCTGAAACAGAGGAGAAGAAC $\begin{array}{llllllllllllllllllll}S & N & N & I & Q & S & I & V & K & E & C & P & P & S & E & T & E & E & K & N\end{array}$ 841 CGGATCGCTGCTGCTGTCTTCTACTCCATCAGCCTGACCCAGCAGGGCCTGCAGGGCGTG

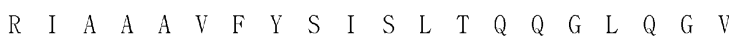

901 GGACTCGGCACCTTCCTCATAAAGCGAGTGGTCAAGGAGCTGCAGAAGGAGTTTCCTCAT

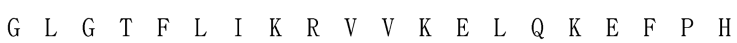
961 CTGGGGGCCTTTTCCAGCCTGTCACCTATACCCGGATTCACCAAGTGGCTGCTGGGCCTT

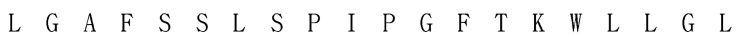
1021 CTGAATGTGCAGGGAAAGGAGTATGGGAGGAACGAGCTGTTCACAGACTCAGAGTGCAAA $\begin{array}{llllllllllllllllllll}\text { L } & N & \text { V } & \text { Q } & G & \text { K } & \text { E } & \text { Y } & G & \text { R } & \text { N } & \text { E } & \text { L } & \text { F } & \text { T } & \text { D } & \text { S } & \text { E } & \text { C } & \text { K }\end{array}$ 1081 GAAATCGCAGAGGTCACGGGCGACCCTGTTCACGAGAGCCTCAAGGGTCTCCTGAGCAGT

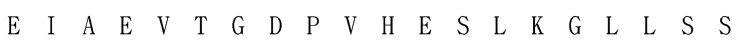
1141 GGTGAGTGGGCGAAGTCTGAGAAGCTGGCACAGGCACTGCAGGGGCACTGATGAGACTG

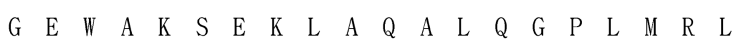
1201 TGTGCCTGGTACCTTTACGGTGAGAAGCACCGATACGCCCTCAATCCAGTGGCCAACTTC

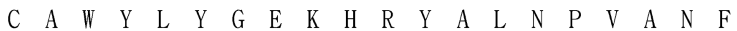
1261 CACCTGCAGAACGGGGCTGTGATGTGGCGTATCAACTGGATGGCTGACAGCAGCCTCAAA $\begin{array}{lllllllllllllllllllll}H & \mathrm{~L} & \mathrm{Q} & \mathrm{N} & \mathrm{G} & \mathrm{A} & \mathrm{V} & \mathrm{M} & \mathrm{W} & \mathrm{R} & \mathrm{I} & \mathrm{N} & \mathrm{W} & \mathrm{M} & \mathrm{A} & \mathrm{D} & \mathrm{S} & \mathrm{S} & \mathrm{L} & \mathrm{K}\end{array}$ 1321 GGCCTCACCAGCTCGTGCGGCCTCATGGTCAACTACCGTTACTACCTGGAGGAGACCGGC $\begin{array}{lllllllllllllllllllll}\text { G } & L & T & S & S & C & G & L & M & V & N & Y & R & Y & Y & L & E & E & T & G\end{array}$ 1381 CCCAACAGCATCTCCTACCTGGGCTCCAAGAACATCAAAGCTTCCGAGCAGATCCTCAGC $\begin{array}{llllllllllllllllllll}P & N & S & I & S & Y & L & G & S & K & N & I & K & A & S & E & Q & I & L & S\end{array}$ 1441 CTGGTAGCCCAGTTCCAGAGCAACAGCAAACTCTAGGGACATCCTGCCCAGCGCTTGGCC $\begin{array}{lllllllll}L & V & A & Q & F & Q & S & N\end{array}$ CTGCTCAGAAAGGAGGCTGTATTCTGATGGGCCAGCGCTGCTCACCACAGCAACCACTCA GGAGGCCACACCTCAGCTGTCACTGTGCTGGCGGACTCACTGGTTGGAGTGGTGGTGGTT TTGGGTACACCTGCCCTGAGGATGTCACTGTGCTTCTCCAAAAGCCCTTGCTGCTGCCCC CACAGCCTGTGCTTTCAGAAAGCTCTACAGATGCAGCCACAGGCCGCCCAGGACGGAGCC CAGAGCACAGACCCTGTAGAGTACAGAGAGTTGGCAGTCATGTCCTCTATTCGGGAGAGG GCTAAGGTCTGTGCCGTGGCTGCTACCACAGCTTAAGCTCAGACTAGGGAGACCTTGTGG TGTGCACAGGGTGTGATCTGCAACCCAGGGATGCTGCTACTTGAGGCCAGAATAGGCTCG TAGGGTTTAAATGAGATCCCAGTTCATAATGAACTGAACAGTAAAGAACAAATTTGTTCT GTAAACATTAAACATGATTGTTCACTGTAAAAAAAAAAAA

Fig. 1. Nucleotide sequence of rat malonyl-CoA decarboxylase cDNA and its deduced amino acid sequence. The ATG, which may serve as a translation start site, is shown by white-on-black type. The mitochondrial presequence is indicated in bold type at the beginning of the sequence and the positive arginine residues are framed. Amino acids are presented in single letter code. The Ser-LysLeu (SKL) peroxisomal-targeting sequence at the C-terminus is shown by white-on-black type.

was initiated by the addition of decarboxylase. The increase in absorbance at $340 \mathrm{~nm}$ was then determined.

\section{Results}

Cloning and sequencing of malonyl-CoA decarboxylase gene from rat brain cDNA library A rat-expressed sequence tag that is related to goose MCD was initially identified from searches of public databases from the National Center for Biotechnology Information (Bethesda, USA). Perusal of rat and goose DNA sequence databases demonstrated a closely related homologue of MCD in both species. By using various protocols, including PCR methods and screening a brain cDNA library, we obtained a full-length sequence of rat MCD. Briefly, a fragment of rat MCD cDNA (amplified by PCR based on the EST sequence and its length was $106 \mathrm{bp}$ ) was used as a probe to isolate a full-length rat cDNA from a rat brain cDNA library. Of the clones, the longest has an insert of 2020 bp that comprised 491 amino acid residues with a single open-reading frame. Its deduced amino acid sequence had a $84 \%$ and $78 \%$ of identity with those of humans and geese, respectively. The sequence of the 491 amino acid (molecular mass 54,610 Da) from rat protein is illustrated in Fig. 1, where it is compared with the reported MCDs from humans, geese, and $R$. trifolii (Fig. 2). MCD from rats shared a $65.6 \%, 87.2 \%$, and $28.7 \%$ identity with those from geese (Jang et al., 1989), humans (Gao et al., 1999), and $R$. trifolii, respectively. This sequence analysis 
Rat

Human

Goose

R. $\operatorname{tr} \mathrm{i}$

Rat

Human

Goose

R.tri

Rat

Human

Goose

R. $\operatorname{tri}$

Rat

Human

Goose

R.tri

Rat

Human

Goose

R.tri
MRGLGTSLLR-ATTLLPLRYPPP------RPPGPRGPRLCSGLTAS--MRGFGPGLT--ARRLLPLRLPP------RPPGPRLASGQAAGALER-MRGLRRGLSRLGPRLGPWAVPRSLRRVLRAAGPWRGQSSAGSVSERGG MSEASFFTDMLQSITDRGRQLLFSGA

A-MDELLRRAVPPTPAYELREKTPAPAEGQCADFVSFYGGLAE-AAQRAELLGRLAQGFG A-M̄DELLRRAVPPTPAYELREKTPAPAEGQCADFVSFYYGGLAE-TAQRAELLGRLARGFG ASMEEVLSRSVPLLPPYETKEKAPPPAERRSAEFVRYYRGLEA-GSRRAELLGCLARDFG RATQVAAKVDLQTLCEMLLSSRGEASGMALAÄEILDRWGALESEGAQKFLLLI--LHEKFG

VDHGQVAEQSAGVLRLRQQSREAAVLLAEDRLRYALVPRYRSLFHHISKLDGGVRFLVQ VDHGQVAEQSAGVLHLRQQQRESAVLLQAEVRLRYALVPRYRGLFHHISKLDGGVRFLVQ ADHGRVAEFSAKVLQAREQEREQGALLQAEDRVRYYLTPRYRALFQHLGRLEGGLRFLVE PD̄TTKLDQAIDKY-RADKSSAAI IALLHQAAE-------PRRQELLRRLNHAPNGTAKLVR

LRADLLEAQALKL VEGPHVREMNGVLKSMLSEWFSSGFLNLERVTWHSPCEVLQKISDCE LRADLLEAQALKKLVEGPDVREMNGVLKGMLSEWFSSGFLNLERVTWHSPCEVLQKISEAE LRGDLVEGLAAK̈AVDGPHVKEMSGVLKNMLSEWFSTGFLNLERVTWQSPCEVLQK ISDSE MRQQLLASKDQSA--GYHA--LDADFTHLFGSWFNRGFLTLRPIDWTTPAY ILEKI IKYE

AVHPVKNWMDMKRRVGPY-RRCYFFSHCSTPGDPLVVLHVALTGDISNNIQSIVKECPPS AVHPVKNWMDMKRRVGPY-RRCYFFSHCSTPGEPLVVLHVALTGDISSNIQAIVKEHPPS AVHPVRNWVDLKRRVGPY-RRCYFFSHCAIPGEPLI ILHVALTSDISSSIQSIVKDVESL AVHEIAGWEELRRRLAPADRRCFAFFHPRLADEPLVFVEVALTRSVPRAIGDVLD--EGR
Rat

Human

Goose

R.tri

Rat

Human

Goose

R.tri

Rat

Human

Goose

R.tri

Rat

Human

Goose

R.tri
ETEEKNRIAAAVFYSISLTQQGLQGVGLGTFLIKRVVKELQKEFPHLGAFSSLSPIPGF' ETEEKNKITAAIFYSISLTQQGLQGVELGTFLIKRVVKELQREFPHLGVFSSLSPIPGF' ETEDAEKITTAIFYSISLAQQGLQGVELGNHLIKRVVKELQKDLPQIEAFSSLSPIPGF' EQINADEATTAVVFYSISNCQDGLRGISFGGNFLIKQVVVEDLRRDLPGLKNFVTTLSPVPGF.

KWLLGLLNVQGKEYGRNELFTDSECKEIAEVTGGDPVHESLKGLLSSGEWAKSEKLAQAL KWLLGLLNSQTKEHGRNELFTDSECKEISEITGGPINETLKLLLSSSEWVQSEKLVRAL KWLVGLLSSQTKELGRNELFTESERQEISEITTEDSTTETLKKLLTNSEWVKSEKLVKAL] RWLAK---------ARPETLTTA--------------------_LDDPNWPDDKKTATEV]

GPLMRLCAWYLYGEKH-RGYALNPVANFHLQNGAVMWRINWMADSSLKGLTSSCGLMVN TPLMRLCAWYLYGEKH-RGYALNPVANFILQNGAVLWRINWMADVSLRGITGSCGLMAN SPLMRLCAWYLYGEKH-RGYALNPVANFHLQNGAELWRINWMGDTSPRGIAASCGMNVN RVLLPLAARYFLVVERTPEGRPVDPVARFHLGNGARLERLNFLGDRSAKAMQQAHGLMVN

RYYLEETGPNSISYLGSKNIKASEQILSLVAQFQSNSKL RYFLEETGPNSTSYLGSKI IKASEQVLSLVAQFQKNSKL RYFLEDTASNSAAYLGTKHIKASEQVLSFVSQFQQNSKL LȲKLDDIVANHEALAQRGEVIASPAVKSLLNQNDEGRSGGNGQQGSRPFAQIVNSTLGGI

Fig. 2. Sequence alignment of the deduced amino acid sequences of the rat malonyl-CoA decarboxylase with the homologous sequence. An asterisk indicates cysteines in rat malonyl-CoA decarboxylase $\left(^{*}\right)$ and mitochondrial targeting sequence is underlined.

Rat

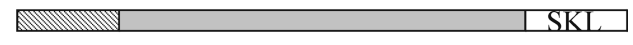

Goose

Human

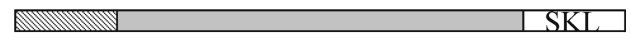

Rhizobium trifolii

Fig. 3. Structure of malonyl-CoA decarboxylase from various

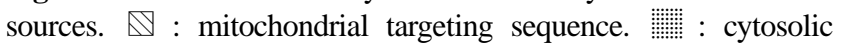
form. $\square$ : peroxisomal targeting sequence.

suggests that the rat and human homologues appear to have shorter N-terminal regions than geese, which may be involved in mitochondrial targeting. MCD from geese includes a 33 amino acid N-terminal motif, which forms an amphipathic helix structure that corresponds to the mitochondrial targeting sequence (Fig. 2). In spite of the difference in amino acid length, those from humans and rats have 25 amino acid stretches, which could be predicted as the mitochondrialtargeting motif; rat enzyme especially has a PRLCSG cleavage signal by mitochondrial processing peptidase. This enzyme contains a perfect match to the consensus sequence for the peroxisomal targeting signal, Ser-Lys-Leu $\mathrm{COOH}_{\mathrm{C}}$, which is strictly conserved in humans and geese. MCD may then contribute to the peroxisomal metabolic processes.

Tissue distribution of malonyl-CoA decarboxylase We also analyzed the expression of malonyl-CoA decarboxylase mRNA in different rat tissues. A multitissue Northern blot that contained poly (A)+ RNA from 8 different tissues was hybridized with a radiolabeled probe (Fig. 4). A $2.0 \mathrm{~kb}$ rat malonyl-CoA decarboxylase transcript was detected in all of the tissues examined. However, the abundance of the rat malonyl-CoA decarboxylase mRNA appeared to vary considerably with a strong expression in the heart and liver. The levels of mRNA were much lower in the brain, skeletal muscle, and kidney, and low but detectable in all other tissues.

Expression and purification of recombinant malonyl-CoA decarboxylase The recombinant protein that was fused with glutathione S-transferase (GST) to discriminate it from the $E$. coli enzyme was expressed at a high level in a soluble form, as well as an insoluble form, and could be efficiently purified by glutathione-affinity chromatography. The recombinant rat MCD was purified to apparent homogeneity from the $E$. coli in which this enzyme was expressed. As shown in Fig. 5, the GST-fusion 

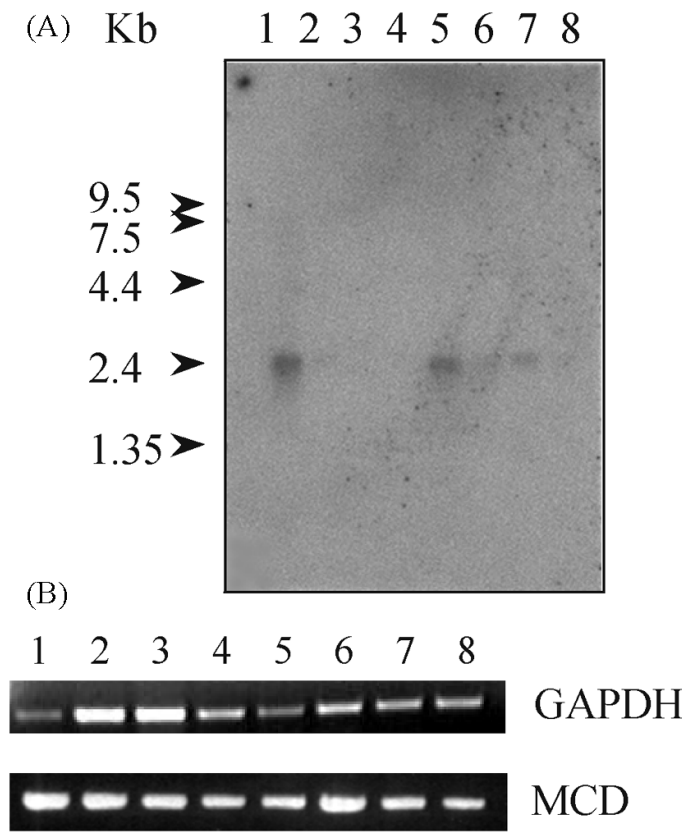

Fig. 4. Tissue distribution of rat malonyl-CoA decarboxylase. (a) Northern blot analysis. Each lane contains approximately. $2 \mu \mathrm{g}$ of poly $\mathrm{A}^{+} \mathrm{RNA}$ from the following rat tissue. Lane 1: heart. Lane 2: brain. Lane 3: spleen. Lane 4: lung. Lane 5: liver. Lane 6:skeletal muscle. Lane 7: kidney. Lane 8: testis. (b) semiquantitative RT-PCR. RNA was extracted from various tissues from adult rat. 1. brain, 2. heart, 3. kidney, 4. liver, 5. lung, 6. skeletal muscle, 7 . spleen, 8 . testis.

protein migrated to $\sim 80 \mathrm{kDa}$ in a SDS-PAGE analysis. After the GST carrier was removed by thrombin cleavage, the purified recombinant protein moved as a single band at $\sim 54 \mathrm{kDa}$, which correlates with what we calculated from the cDNA sequence. Although the purified recombinant protein has a different degree of (or lack of) glycosylation from the original rat enzyme, the protein has in vitro biological activity to generate the acetyl CoA from malonyl CoA.

Malonyl-CoA decarboxylase activity of the overexpressed enzyme The purified MCD enzyme was used to

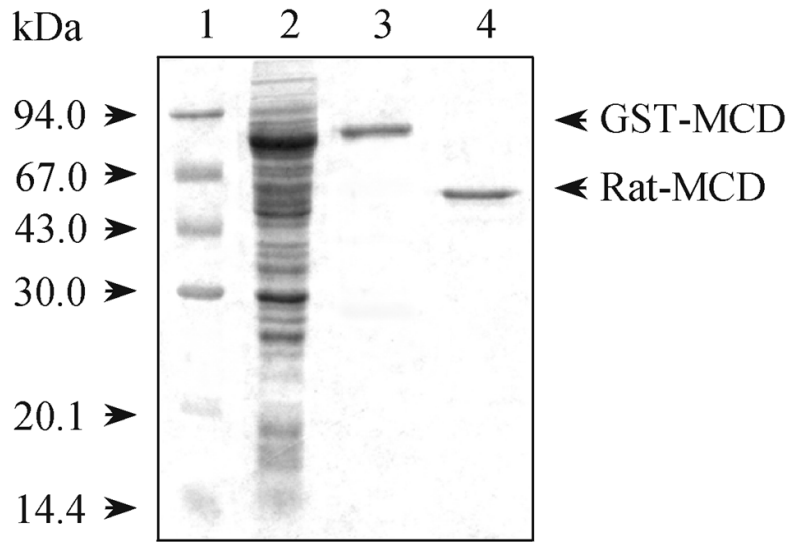

Fig. 5. SDS-PAGE analysis of protein extracts containing malonyl-CoA decarboxylase. SDS-PAGE analysis of purified malonyl-CoA decarboxylase using glutathione affinity column. Lane 1: size marker. Lane 2: soluble fraction induced with 1 mM IPTG. lane 3: GST-MCD is indicated by an arrow. Lane 4: purified malonyl-CoA decasrboxylase. The sizes of standard proteins are indicated on the left side. Affinity gel chromatography and cleavage of GST from GST-MCD was carried out as described under "Experimental Procedures."

characterize the biochemical properties in vitro. The substrate dependence curves for MCD were consistent with MichaelisMenten kinetics that showed typical hyperbolic substrate dependence (Fig. 6). From the double-reciprocal plots, the $K_{m}$ value for rMCD was $6.8 \mathrm{nM}$, and the $V_{\max }$ value was 42.6 $\mu \mathrm{mole} / \mathrm{min} / \mathrm{mg}$ protein. Specific activity was also calculated to be 43.4 unit/mg. Judging from the $\mathrm{Km}$ values, the rat $\mathrm{rMCD}$ had a high affinity for the substrate compared with those of humans, geese, and $R$. trifolii.

\section{Discussion}

We cloned rat malonyl-CoA decarboxylase cDNA from the rat brain cDNA library in order to gain insight into the function and regulation of malonyl-CoA decarboxylase. We show here that the recombinant MCD protein has high intrinsic malonyl CoA decarboxylase activity, which confirms

Table 1. Properties of malonyl-CoA decarboxylases from various sources.

\begin{tabular}{cccccc}
\hline Sources & Molecular weight & $\begin{array}{c}\text { Subunit molecular } \\
\text { weight }\end{array}$ & Subunit composition & $K_{m}$ & $V_{\text {max }}$ \\
\hline Rat & $\mathrm{kDa}$ & $\mathrm{kDa}$ & & $\mathrm{mM}$ & unit/mg \\
Human $^{\mathrm{a}}$ & & 54 & & 0.068 & 42.6 \\
Goose $^{\mathrm{b}}$ & 186 & 46 & Homotetramer & 0.10 & 80 \\
R. trifolii & & 47 & Homotetramer & 0.47 & 52 \\
\hline
\end{tabular}

ataken from Ref. (Katherine et al., 1999)

${ }^{b}$ taken from Ref. (Kolattukudy et al., 1981)

ctaken from Ref. (An and Kim, 1998) 

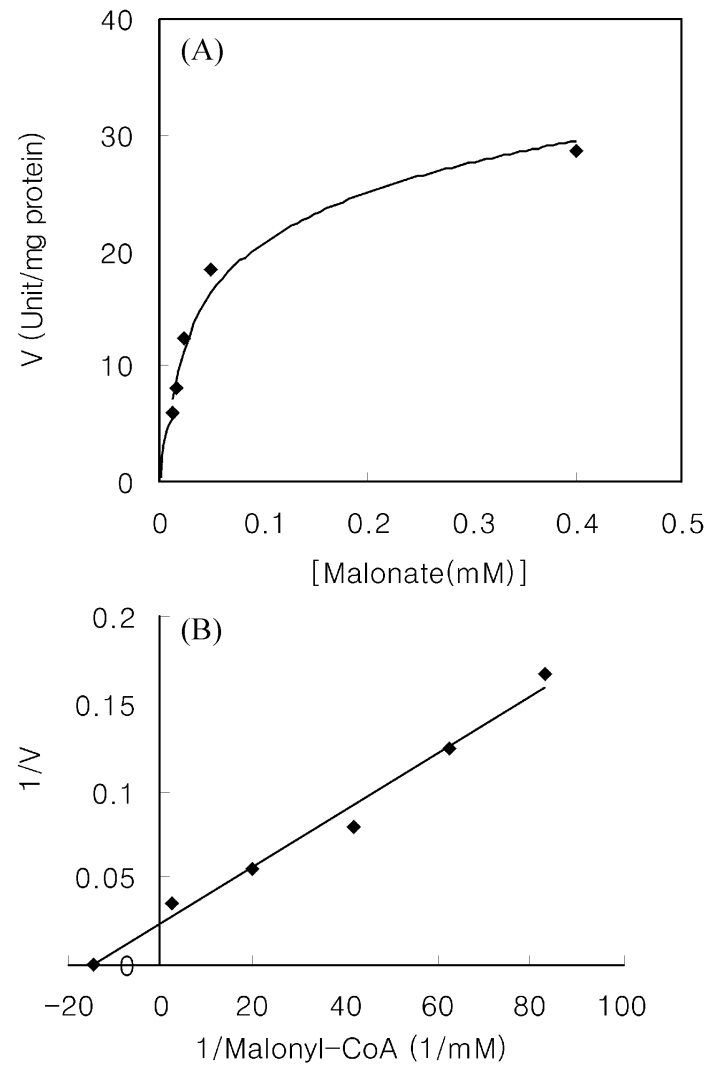

Fig. 6. Effect of malonyl-CoA concentration on the rate of decarboxylation of malonyl-CoA by the purified enzyme.

that this gene encodes rat MCD. The full-length cDNA sequence showed a $87.2 \%$ and $65.6 \%$ identity with the cDNA that was cloned previously from the human and goose uropygial gland, respectively. It indicated that this gene is well conserved between birds and mammals. Its deduced amino acid sequence contains 491 amino acid residues, which have a calculated molecular weight of $54.6 \mathrm{kDa}$. In the sequence analysis, we were able to provide the feasible features in the rat MCD structure. The N-terminal portion has a positively charged amphiphilic helix structure known as the mitochondrial targeting sequence, and the C-terminal region ends with a putative peroxisomal (Ser-Lys-Leu $\mathrm{COOH}_{\text {) }}$ targeting motif. Especially, the deduced amino acid sequence of rat MCD has several features of mitochondrial target presequence. First, it contains the compositional tendency of the mitochondrial targeting sequence. They are rich in Ala, Ser, Leu, Arg, but there are no acidic residues (D/E). Second, it represents some loops as amphiphilic loops. Third, it appears to encode the substrate specificity of the mitochondrial processing peptidase. By a cleavage-site motif (PRLCSG) (defined by Gavel around position 31), this evidence suggests that rat MCD is, at least in part, a mitochondrial matrix enzyme. Although its presence and physiological roles in mitochondria remains elusive, the mitochondrial localization of the goose MCD has suggested that this enzyme may first function in removing intramitochondrial malonyl $\mathrm{CoA}$ that is produced by the adventitious activity of propionyl CoA carboxylase. Alternative transcription initiators generated two transcripts from one gene. In the case of the human MCD gene, two types of cDNA were similarly reported. Also, as suggested, three types of MCD may exist as mitochondrial, cytoplasmic, and peroxisomal forms. Thus, each form of MCD (mitochondrial, peroxisomal and cytoplasmic forms) is likely to play a different role in cellular metabolism. The peroxysomal form may catalyze the reaction from malonyl $\mathrm{CoA}$ to $\mathrm{CO}_{2}$ and acetyl $\mathrm{CoA}$, since the $\beta$-oxidation of dicarboxylic fatty acids that occurs exclusively in peroxisomes and malonyl $\mathrm{CoA}$ is the ultimate $\beta$-oxidation product of the odd-chain length dicarboxylic fatty acids.

From a Northern blot analysis and semi-quantitative PCR analysis, a single transcript about $2 \mathrm{~kb}$ in size is distributed over a wide range of rat tissues. It is interesting to note that the expression level of malonyl-CoA decarboxylase is highest in the heart and liver, the two tissues that have the greatest dependence on fatty acids as an energy source. A lot of evidence has accumulated during the last few years. It indicates that malonyl CoA is a cytosolic signal of glucose sensing, particularly in the liver, heart, and adipose. These tissues derive significant amounts of energy from fatty acid oxidation. Furthermore, the interaction between malonyl CoA and carnitine palmitoyltransferase I is considered a pivotal site of intervention in diabetes and obesity (Prentki, 1996; McGarry and Brown, 1997). Previous studies have implicated that patients show several phenotypes that are similar to deficiencies in mitochondrial fatty acid oxidation, including diet-induced and infection-induced vomiting, seizures, hypoglycemia, and organic aciduria, as well as cardiomyopathy (Yano et al., 1997). Thus, MCD is likely to be involved in the regulation of lipid metabolism and the cytosolic malonyl CoA concentration in mammalian cells in many aspects.

In this study, we describe the cloning of a novel rat MCD cDNA, the expression of recombinant protein, and its biochemical characterization. If MCD is implicated in the regulation of lipid metabolism and other cellular functions in mammalian cells, it could be a clue for the molecular and metabolic basis of malonyl CoA in the eukaryotic kingdom, as well as in the lower kingdom, and for the pathological mechanism of human diseases, such as aciduria.

Acknowledgments This work was supported by a Korea Research Foundation Grant (KRF-2000-015-DP0288).

\section{References}

An, J. H. and Kim, Y. S. (1998) A novel gene cluster encoding malonyl-CoA decarboxylase (MatA), malonyl-CoA synthetase (MatB) and a putative dicarboxylate carrier protein (MatC) in Rhizobium trifolii: cloning, sequencing, and expression of the enzymes in Escherichia coli. Eur. J. Biochem. 257, 395-402. 
An, J. H., Lee G. Y., Song, J. H, Lee, D. W. and Kim, Y. S. (1999) Properties of malonyl-CoA decarboxylase from Rhizobium trifolii. J. Biochem. Mol. Biol. 32, 414-418.

Babior, B. M. (1973) Cleavage of coenzyme B12 by methylmalonyl Coenzyme A mutase. J. Biol. Chem. 248, 14451450.

Byun, H. S. and Kim, Y. S. (1995) CoA transferase and malonylCoA decarboxylase activity of malonate decarboxylase from Acinotobacter calcoaceticus. J. Biochem. Mol. Biol. 28, 107111.

Courchesne-Smith, C., Jang, S. H., Shi, Q., DeWille, J., Sasaki, G. and Kolattukudy, P. E. (1992) Cytoplasmic accumulation of a normally mitochondrial malonyl-CoA decarboxylase by the use of an alternate transcription start site. Arch. Biochem. Biophys. 298, 576-586.

Dickson, A. C., McEvoy, J. A. and Koeppen, A. H. (1994) The cellular localization of malonyl-coenzyme A decarboxylase in rat brain. Neurochem. Res. 19, 1271-1276.

Eun, S. H., Kim, D. J. and Kim, Y. S. (2001) Acinetobacter calcoaceticus Glucose-1-phosphate thymidytransferase; Cloning, sequencing, and expression in E. coli. J. Biochem. Mol. Biol. 34, 230-236.

Gregg, A. R., Warman, A. W., Thorburn, D. R. and O'Brien, W. E. (1998) Combined malonic and methylmalonic aciduria with normal malonyl-coenzyme A decarboxylase activity: a case supporting multiple aetiologies. J. Inherit. Metab. Dis. 21, 382390.

Haan, E. A., Scholem, R. D., Croll, H. B. and Brown, G. K. (1986) Malonyl coenzyme A decarboxylase deficiency. Clinical and biochemical findings in a second child with a more severe enzyme defect. Eur. J. Pediatr. 144, 567-570.

Jang, S. H., Cheesbrough, T. M. and Kolattukudy, P. E. (1989) Molecular cloning, nucleotide sequence and tissue distribution of malonyl-CoA decarboxylase. J. Biol. Chem. 264, 3500-3505.

Kaushik, V. K., Young, M. E., Dean, D. J., Kurowski, T. G., Saha, A. K. and Ruderman, N. B. (2001) Regulation of fatty acid oxidation and glucose metabolism in rat soleus muscle: effects of AICAR. Am. J. Physiol. Endocrinol. Metab. 281, E335E340.

Kim, Y. S. and Kolattukudy, P. E. (1978a) Purification and properties of malonyl-CoA decarboxylase from rat liver mitochondria and its immunological comparison with the enzymes from rat brain, heart, and mammary gland. Arch. Biochem. Biophys. 190, 224-246.

Kim, Y. S. and Kolattukudy, P. E. (1978b) Malonyl-CoA decarboxylase from the uropygial gland of waterfowl: purification, properties, immunological comparison, and role in regulating the synthesis of multimethyl-branched fatty acids. Arch. Biochem. Biophys. 190, 585-597.

Kolattukudy, P. E., Poulose, A. J. and Kim, Y. S. (1981) MalonylCoA decarboxylase from avian, mammalian, and microbial sources. Methods Enzymol. 71C, 150-153.

Kozak, M. (1996) Interpreting cDNA sequences: some insights from studies on translation. Mamm. Genome 7, 563-574.

Krawinkel, M. B., Oldigs, H. D., Santer, R., Lehnert, W., Wendel, U. and Schaub, J. (1994) Association of malonyl-CoA decarboxylase deficiency and heterozygote state for hemoglobin C disease. J. Inherit. Metab. Dis. 17, 636-637.

Lee, H. Y. and Kim, Y. S. (2001) Identification of amino acid residues in the carboxyl terminus required for malonateresponsive transcriptional regulation of MatR in Rhizobium leguminosarum bv. trifolii. J. Biochem. Mol. Biol. 34, 305-309.

McGarry, J. D. and Brown, N. F. (1997) The mitochondrial carnitine palmitoyltransferase system. From concept to molecular analysis. Eur. J. Biochem. 244, 1-14.

Park, S. J. and Cho, Y. D. (2000) Studies on the active site of the Arabidopsis thaliana S-Adenosylmethionine Decarboxy: Lys ${ }^{81}$ residue involvement in catalytic activity. J. Biochem. Mol. Biol. 33, 69-74.

Prentki, M (1996) New insights into pancreatic beta-cell metabolic signaling in insulin secretion. Eur. J. Endocrinol. 134, 272-286.

Ozand, P. T., Nyhan, W. L., al Aqeel, A. and Christodoulou, J. (1994) Malonic aciduria. Brain. Dev. 16, 7-11.

Sacksteder, K. A., Morrell, J. C., Wanders, R. J., Matalon, R. and Gould, S. J. (1999) MCD encodes peroxisomal and cytoplasmic forms of malonyl-CoA decarboxylase and is mutated in malonyl-CoA decarboxylase deficiency. J. Biol. Chem. 274, 24461-24468.

Sambrook, J., Fritsch, E. F. and Maniatis, T. (1989) Molecular cloning: a laboratory manual, 2nd ed. Cold Spring Harbor Laboratory Press, Cold Spring Harbor, New York.

Scrutton, M. C. and Utter, M. F. (1967) Pyruvate carboxylase IX, some properties of the activation by certain acyl derivatives of coenzyme A. J. Biol. Chem. 242, 1723-1735.

Sha, Z., Stabel, T. J. and Mayfield, J. E. (1994) Brucella abortus catalase is a periplasmic protein lacking a standard signal sequence. J. Bacterial. 176, 7375-7377.

Yano, S., Sweetman, L., Thorburn, D. R., Mofidi, S. and Williams, J. C. (1997) A new case of malonyl coenzyme A decarboxylase deficiency presenting with cardiomyopathy. Eur. J. Pediatr. 156, 382-383. 